\title{
Self-assembled bionanostructures: proteins following the lead of DNA nanostructures
}

\author{
Helena Gradišar ${ }^{1,2^{*}}$ and Roman Jerala ${ }^{1,2^{*}}$
}

\begin{abstract}
Natural polymers are able to self-assemble into versatile nanostructures based on the information encoded into their primary structure. The structural richness of biopolymer-based nanostructures depends on the information content of building blocks and the available biological machinery to assemble and decode polymers with a defined sequence. Natural polypeptides comprise 20 amino acids with very different properties in comparison to only 4 structurally similar nucleotides, building elements of nucleic acids. Nevertheless the ease of synthesizing polynucleotides with selected sequence and the ability to encode the nanostructural assembly based on the two specific nucleotide pairs underlay the development of techniques to self-assemble almost any selected three-dimensional nanostructure from polynucleotides. Despite more complex design rules, peptides were successfully used to assemble symmetric nanostructures, such as fibrils and spheres. While earlier designed protein-based nanostructures used linked natural oligomerizing domains, recent design of new oligomerizing interaction surfaces and introduction of the platform for topologically designed protein fold may enable polypeptide-based design to follow the track of DNA nanostructures. The advantages of protein-based nanostructures, such as the functional versatility and cost effective and sustainable production methods provide strong incentive for further development in this direction.
\end{abstract}

Keywords: Self-assembly, Protein nanostructures, DNA nanostructures, Protein origami

\section{Introduction}

The versatility of biopolymers can be used to rationally design new molecules and assemblies with structures and functionalities unseen in nature. The ability of biopolymers to self-assemble into complex shapes and structures defined at the nanometer scale, and our competence of sustainable large-scale production using cell factories makes them highly desirable for diverse technological applications. In the rapidly-growing research area of modern nanobiotechnology the natural components polypeptides and nucleic acids have been employed as building blocks for the assembling of new designed nanostructures and nanomaterials. Bionanotechnologists have in the last decades achieved important advances in protein-based and particularly DNAbased responsive nanostructures, which can now be designed to self-assemble into almost any selected shape.

Molecular self-assembly as the main organizing principle of biological systems is also a widely applied strategy in the nanotechnology as the driving force for the assembly of

\footnotetext{
*Correspondence: helena.gradisar@ki.si; roman.jerala@ki.si

${ }^{1}$ Department of Biotechnology, National Institute of Chemistry, Ljubljana, Slovenia ${ }^{2}$ Excellent NMR - Future Innovation for Sustainable Technologies, Centre of Excellence, Ljubljana, Slovenia
}

artificial nanostructures. In self-assembly the final structure is encoded by interactions of its building elements defined by their properties and the order of building blocks within the linear polymer. The shapes and functions of both, DNA- and protein-based nanostructures are encoded by the sequence of their constituents, nucleotides and amino acids. Additionally, the architecture of both type of the nanostructures can be affected also by the environmental factors, such as solvent, $\mathrm{pH}$, temperature and building blocks concentration.

DNA nanostructures are based on the Watson-Crick nucleic base complementarity. There are only two different base pairs based on a specific pairwise interaction, where stacking with neighboring pairs underlies the formation of stable double-helical domains that serve as the nanostructural building blocks. Some of the most spectacular examples of the potentials of nanobiotechnology have been demonstrated by DNA-based nanostructures. In the nature the primary function of nucleic acids are the storage, processing and mediation of genetic information; however natural structures such as aptameres, telomeres and partially the ribosome as one 
of the key and most complex nanodevices are formed by nucleic acids assembled into 3D structures. The relevance of the physiological role of nucleic acids that perform their function in form of self-assembled noncoding RNA transcripts is still unknown. On the other hand artificial rationally designed DNA nanostructures, which utilize a narrower subset of interactions from aptameres, can adopt a huge diversity of 2D or 3D shapes [1-5].

In contrast to designed DNA nanostructures, the rational design of protein nanostructures is much more complicated due to the complex cooperative interactions between amino acids stabilizing the fold of native proteins. The comparison of some features of selfassembled DNA- and protein nanostructures is presented in Figure 1. Structural folding of most natural proteins still cannot be easily predicted from their primary structure due to contribution of many cooperative and long-range interactions between amino acids, therefore de novo design of completely new protein folds is even more challenging.

However, a significant progress has been recently achieved in the development of strategies for building artificial self-assembled bionanostructures, and a range of both, DNA- and protein nanostructures rapidly increased in last two decades. In this review we mainly focus on protein-based nanostructure strategies, while DNA nanotechnology has been discussed in detail in many recent reviews [6-12].

\section{Designed DNA nanostructures}

In 1982, Seeman proposed to use DNA as the structural material for the bottom-up self-assembly [13] and he is accepted as the founder of the field of DNA nanotechnology. Since then, DNA-based self-assembly achieved spectacular results relying on the base-pairing specificity of nucleotides, using DNA synthesis technology, computer based design and, above all, imaginative design. Over the last three decades self-assembled DNA nanostructures have been extensively studied and several different approaches for building DNA nanostructures have been developed. Self-assembled DNA nanostructures range from $3 \mathrm{D}$ structures with a well-defined shape $[2,4,14-17]$ to a variety of complex dynamic DNA devices [8,18-20]. This avenue of research also spawned DNA computing [21,22] and design of dynamic devices $[8,23,24]$, which are however beyond the scope of this review.

DNA self-assembly is a robust and flexible biomimetic strategy for molecular construction that is directed by the information embodied in the nucleotide sequence. Development of DNA nanostructures encompasses several different approaches (Figure 2), where the design of nanostructures is based on the assembly of:

- several medium-sized DNA (few 10-100 nucleotides) oligonucleotides that form finite sized nanostructures [14];

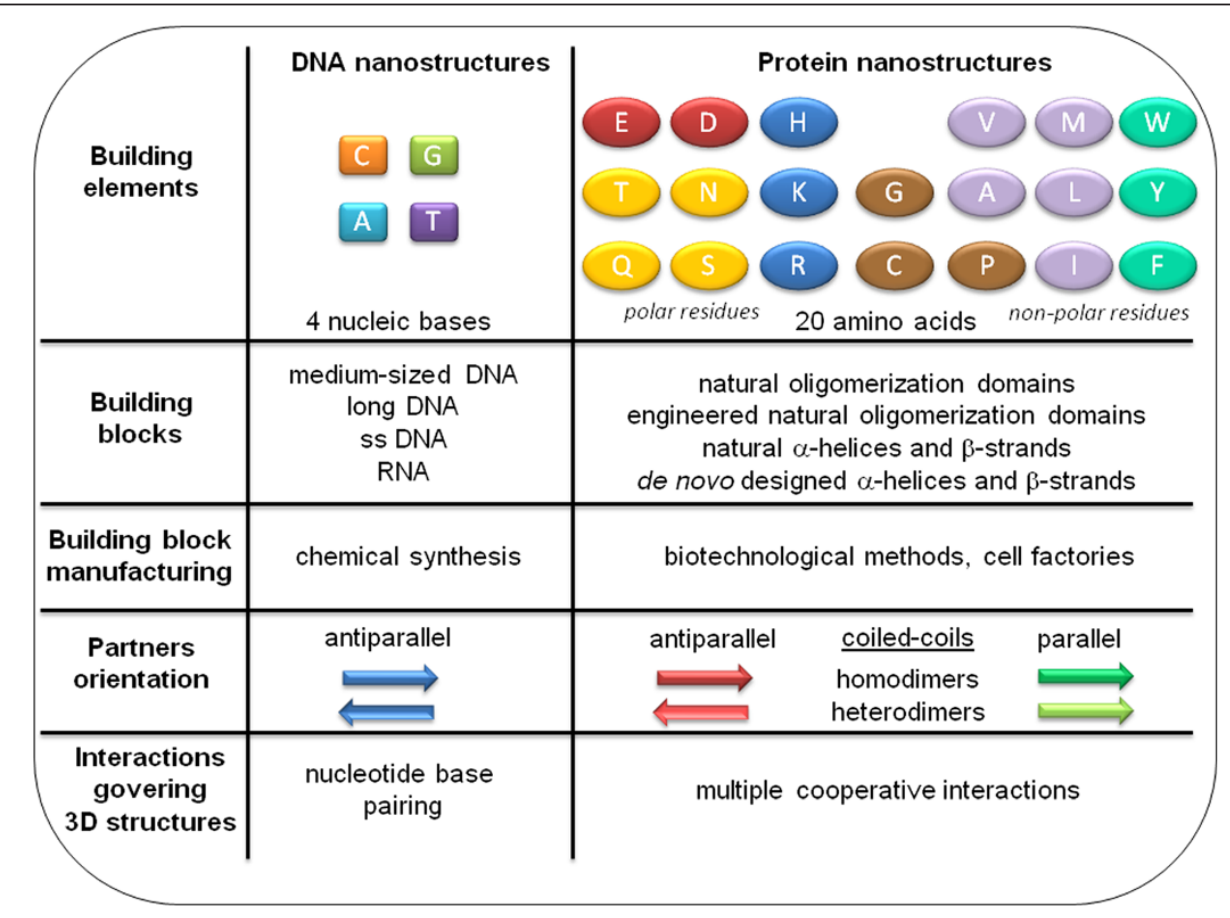

Figure 1 Some features of self-assembled DNA- and protein nanostructures. Natural proteins comprise 20 amino acid residues with diverse properties in comparison to only 4 structurally similar nucleotides, building elements of nucleic acids. The advantages of protein nanostructures include also cheaper manufacturing of building blocks, as well as the multiple cooperative interactions that govering protein nanostructures. 
(a)

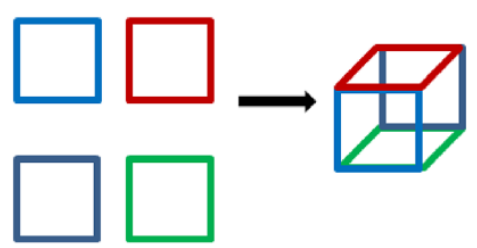

(c)

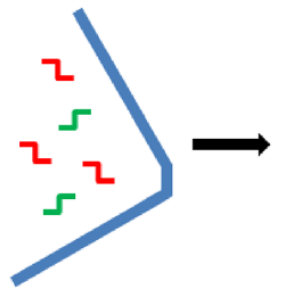

(b)

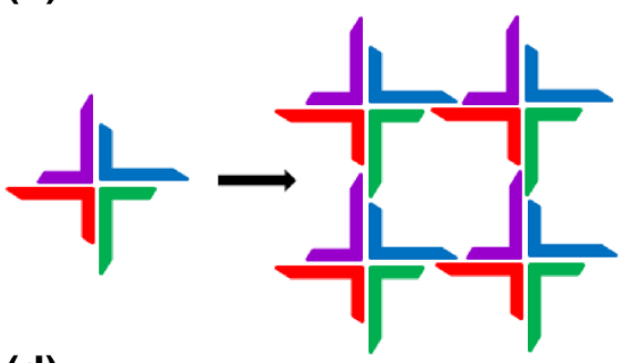

(d)

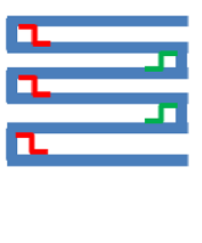

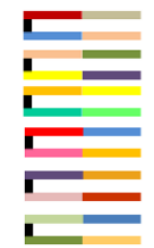

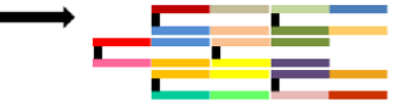

Figure 2 Different approaches for building DNA nanostructures. The design of DNA nanostructure is based on the assembly of several medium-sized oligonucleotides that form either (a) a finite sized nanostructure or (b) assembled building blocks that further oligomerize into a finite sized nanostructure. (c) DNA nanostructure can be assembled from a single long DNA scaffold (blue) and short oligonucleotides (red, green) that hold the scaffold in place. (d) 2D and 3D nanostructures can be constructed by short DNA strands, DNA bricks.

- several medium-sized DNA oligonucleotides that assemble into building blocks that further oligomerize into finite sized structures such as different polyhedra or into lattices $[3,25]$;

- single long DNA scaffold (e.g. encompassing several 1000 nucleotides from the single stranded DNA phage) that is shaped into selected structure by the addition of short oligonucleotide clamps a.k.a. DNA origami technique, invented by Paul Rothemund [26]. This approach can result in complex 2D or 3D shapes such as molecular raster images, box, sphere etc. [27-30];

- large number of short DNA bricks (32 or 42 nucleotide long strands that form U-shaped brick) that fill the 2D plane or 3D space, where the selected structure is formed by the omission of appropriate DNA bricks from the assembly mixture. Almost any 2D or 3D shape can be formed by this approach $[15,31]$.

An important advantage of DNA-based nanostructures is that it is possible to address the selected positions within the $2 \mathrm{D}$ or $3 \mathrm{D}$ nanostructures at approximately $5 \mathrm{~nm}$ resolution and introduce oligonucleotides with selected functionalities, such as different organic compounds, fluorophores, metal binding groups, proteins etc. into those positions, thereby functionalizing DNA nanostructures [9,32-36].

RNA has the distinct advantage that ssRNA could easily be produced in vivo in order to promote the selfassembly. This property was used to prepare RNA-based scaffolds with attached sites for functional proteins fused to specific sequence RNA binding domains. While those in vivo assembled structures were not well characterized, the scaffold strongly enhanced the reaction yield [37] similar to the DNA-based scaffolded enzymes, where the arrangement of enzymes had been linear [38]. It is hoped that this in vivo approach will be further developed for in vivo applications. ssDNA could also be produced in vivo, demonstrated by the self-assembly of a tetrahedron [39]. Isothermal DNA nanostructure assembly strategy has been developed that could further facilitate future DNA self-assembly in vivo [40].

DNA nanostructures were used to make devices that were functional in the cellular milieu; e.g. drug delivery container that encapsulates cargo, such as therapeutic antibodies, while opening of the container could be controlled by binding of the trigger signals to the aptamer lock that regulates opening of the container only if the triggering signals for both of the two locks are present [41]. DNA origami seems to be stable in vivo indicating that it is relatively protected against nucleases. There are also reports on the use of DNA nanostructures as the constituents of vaccines [42-44]. However real applications of DNA nanostructures are at the moment quite rare and essentially all DNA nanostructures are prepared by chemical synthesis, which limits the technological applications due to the cost and scale of production.

\section{Protein nanostructures}

Proteins provide masterful examples of complex selfassembling nanostructures with properties and functiona- 
lities beyond the reach of any human-made materials. It is estimated that there are only few thousand different protein folds in nature, and recently the number of new determined protein fold basically trickled to a halt despite determination of tens of thousands of new protein structures each year. So far folds of only few small protein domains can be accurately predicted [45-48] and design of completely new folds without resemblance to any of the existing native folds represents even a greater challenge [49].

Larger natural proteins have evolved through combinations of several smaller independently folding domains. Protein oligomerization based on the symmetric oligomerization domains is an important source of suprastructured proteins [50]. Existing protein oligomerization domains have been recognized as suitable building blocks for the predictable bottom-up design of artificial protein nanostructures. Strategies that used modified natural domains, or genetically or chemically linked secondary structure elements for selfassembling, and resulted in formation of symmetric intermolecular protein assemblies, lattices and heterogeneous cage-like assemblies, are described in reviews [51-53].
Recently we presented a new approach where a single polypeptide chain composed of concatenated coiled-coilforming peptides self-assembled into a new topological fold, asymmetric tetrahedron-like cage, which is defined and stabilized by the specific pairing of the coiled-coil-forming segments arranged in a precisely defined order rather than cooperative packing of hydrophobic protein core [54].

\section{Assemblies based on linked natural protein oligomerizing domains}

The first strategy for the creation of designed protein nanostructures relied on interactions between oligomerizing protein domains which typically comprise 100-200 or more amino acid residues. The domains can self-assemble non-covalently, but specifically into larger superstructures. Attempts in this direction have been pioneered with fusion strategy [55]. Two different oligomerizing domains, one promoting dimerization and another one promoting homo-trimerization were linked by a semi-rigid linker (Figure 3a). Several copies of such a fusion protein were able to self-assemble into symmetric small cage-like but

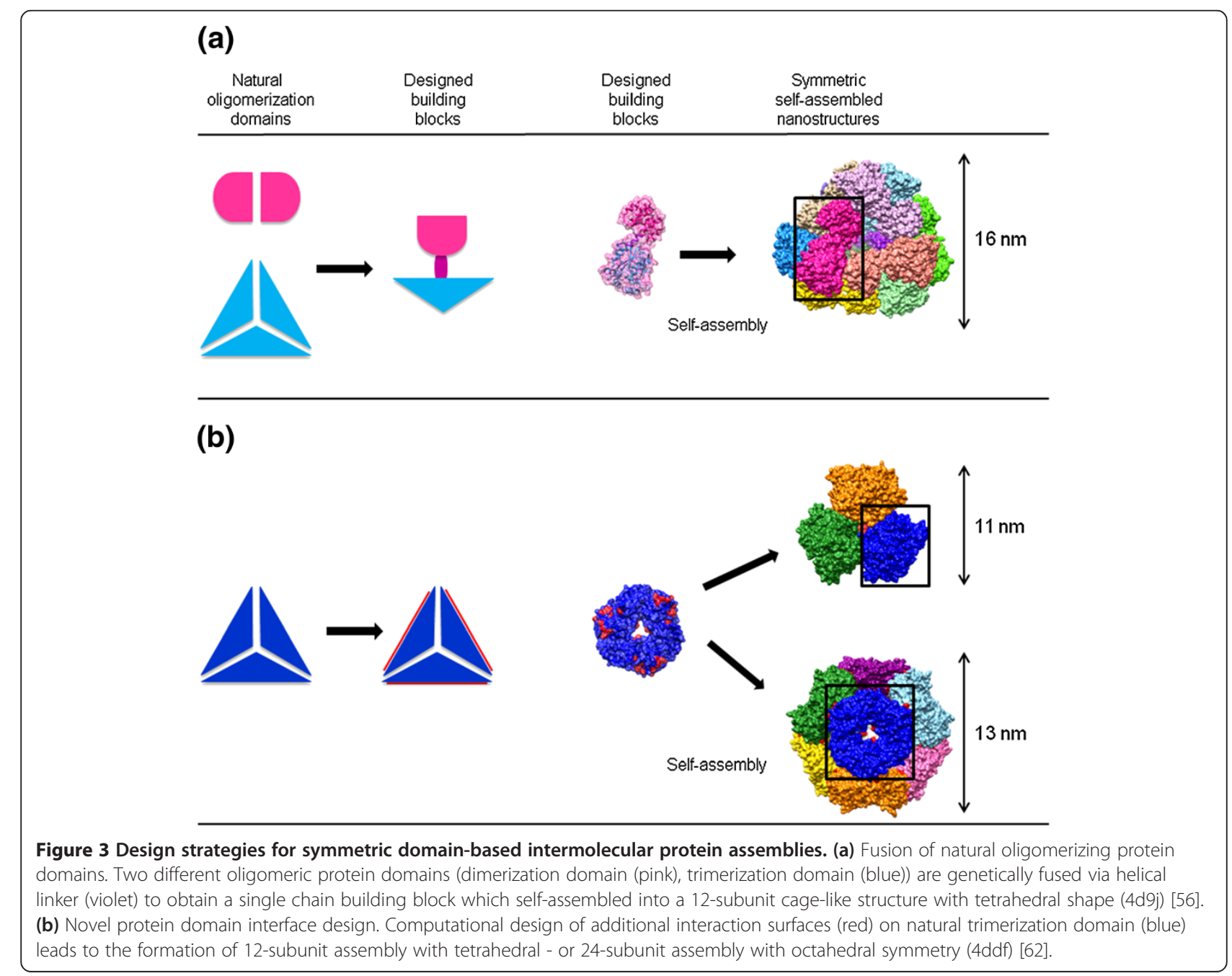


heterogeneous assemblies, or extended fibrils, depending on the length of the helical linker. Recent refinement of the original protein sequence resulted in a homogeneous 12-subunit assembly, confirmed by X-ray crystal structure determination. The structure of this oligomeric nanostructure reveals tetrahedral geometry with $16 \mathrm{~nm}$ diameter $[56,57]$.

This approach provides the possibility to create smart bionanomaterials by regulating the assembly and disassembly. Self-assembly of the fusion protein composed of the dimerizing gyrase $\mathrm{B}$ domain and trimerization domain can be driven by the addition of a small molecule. The addition of pseudo-dimeric gyrase B ligand, coumermycin, induced formation of hexagonal assemblies and its dissociation by the subsequent addition of a monomeric ligand novobiocin, which competes for binding to the same gyrase B site as the pseudodimeric coumermycin [58].

The extended fusion strategy circumvented the problem of connecting two oligomerization domains in a fixed relative orientation which assured well-ordered self-assembled protein nanostructures [59]. They showed that fusion protein can be made by selecting two or more connections between the adjacent oligomers if the two domains are joined along an axis of symmetry that both oligomerization domains share. However this symmetry-matching fusion protein strategy successfully manufactured linear filaments, two-dimensional lattices and large solid aggregates, but is not suitable for designing defined cage-like structures.

\section{Engineering new interaction surfaces into native protein domains}

In the strategies described above the range of suitable protein domains is limited by restrictions regarding the symmetry axes of the natural domains. A step further towards the design of artificial protein nanostructures was done by engineering domain surfaces for weak non-covalent interactions in the self-assembling processes. The analysis of natural contact interfaces between protein domains disclosed the rules governing domain association. The contacting surfaces should be complementary and predominantly non-polar. The contribution of hydrogen bonds and salt bridges at the contact rim is negligible. Employing these rules it was demonstrated that a given protein can be engineered to form new contact interfaces that produced a number of novel assemblies [60]. Algorithm Rosetta for modeling protein-protein interactions [61] enables de novo design of interacting interfaces which can drive the selfassembly of designed proteins into a desired symmetric architecture $[46,62]$. In a recent study, a computational design of protein nanostructures with atomic level accuracy was described [62]. Protein building blocks, based on natural trimeric protein domains were docked together symmetrically to the target packing arrangements and lowenergy protein-protein interaction interfaces were designed between building blocks in order to drive the self-assembly (Figure $3 \mathrm{~b}$ ). The designed proteins assembled into cage-like nanostructures with either tetrahedral or octahedral point group symmetry which was confirmed by crystal structures.

\section{Modular approach for de novo designed protein nanostructures}

The strategies employing oligomerizing protein domains for designing new protein structures, described above, are limited to homologues of known native protein folds. The next generation engineering approaches are based on modules that can be considerably smaller than the typical protein domain. The modules comprise interacting de novo designed secondary structure elements that are predictably combined with specified partners to form larger assemblies. De novo protein design refers to attempts to construct completely new protein sequences for the prescribed structures based on the principles defining the stability and selectivity of building modules; in de novo design the polypeptide sequence is selected by the designer.

Modularity and orthogonality are two foundation concepts of de novo design and engineering of new protein nanostructures. Instead of optimization of the numerous cooperative interactions that underpin the structures of natural proteins, the use of well-understood structural modules, which could be combined into complex nanostructures, was proposed. $\alpha$-helices and $\beta$-strands represent attractive protein folding motifs to serve as building blocks for well-ordered and defined nanostructures with complex architecture [63-67].

The most studied module for building self-assembled protein nanostructures are interacting helical peptides and particularly coiled-coils. They are ubiquitous facilitators of inter- and intramolecular protein-protein interactions and comprise two or more intertwined $\alpha$-helices that are encoded by the characteristic heptad sequence repeat, where residues are labeled with $a b c d e f g$. The non-covalent interactions that drive the formation of coiled-coils are the hydrophobic effects between amino acids at positions $a$ and $d$ that form a hydrophobic core of coiled-coil, and the electrostatic inteactions between the opposite charged residues at positions $e$ and $g$. The rules governing coiled-coil formation, their oligomerization state and interaction partner specificity have been considerably established over the last decades $[68,69]$. On the basis of those rules sets of orthogonal designed coiled-coils as the toolkit for the designed protein assemblies were developed [70-75]. Engineered coiled-coil polypeptides have been used to assemble different nanomaterials: nanofibres [76,77], membranes [78], nanotubes [79], nanostructured films [80], spherical structures [81], responsive hydrogels $[82,83]$, 
spheres [84] etc. Homogeneous nanoparticles with regular polyhedral symmetry, about $16 \mathrm{~nm}$ in diameter, were prepared from single type of polypeptide chains where the two coiled-coil modules with different oligomerization states were joined by a short linker [85]. In another study two oligomerizing coiled-coil peptides were tethered via disulphide bond close to their center. The self-assembled molecules spontaneously curved into the spherical cagelike particles, with a hexagonal-pattern of the cage surface and about $100 \mathrm{~nm}$ in diameter [84]. Another example are discrete circular nanostructures of defined stoichiometry; trimers or tetramers of $<10 \mathrm{~nm}$ were observed when linker between two coiled-coil-forming segments comprising 6-10 residues. Larger colloidal-scale assemblies as well as flexible fibers were formed when shorter linkers limited flexibility between peptides [86].

\section{Designed topological protein folds based on interacting coiled-coil modules}

Recent innovative approach to construct new engineered self-assembled protein nanostructures is based on the concatenated interacting dimerizing modules, comprise up to 45 amino acid residues [54]. The tetrahedral nanostructure was built from only single polypeptide chain; this strategy may appropriately be called designed protein origami as opposed to native protein structures that fold into a defined 3D structure from a single chain.

Rather than folding the structure based on the interactions between residues in the hydrophobic core as for the native proteins, the modular topological design is based on pairwise interactions between concatenated secondary structure elements (coiled-coil-forming segments), whose folding and orthogonality is engineered independently. Orthogonality of used coiled-coil building modules ensures that each segment preferentially binds to its designated partner segment within the same polypeptide chain. The final topology is defined by the sequential order of coiled-coil segments. The topological fold comprises a cavity bounded by coiled-coil dimers as the edges of the polyhedron. This type of modular selfassembly therefore in many aspects resembles the principles of DNA nanostructures [2,3,26], where polyhedra had been constructed based on the complementary DNA segments.

According to this approach long range non-covalent interactions occur between coiled-coil-forming segments, which dimerize independently of the other segments. The coiled-coil-forming segments are concatenated into a precisely defined order with intervening flexible linkers between each segment, to provide the hinge-like flexibility. In the case of a monomeric tetrahedron, which was constructed to demonstrate the principle, the polypeptide chain is composed of 12 designed coiled-coil dimer-forming segments, each forming an orthogonal coiled-coil dimer with its partner segment within the same polypeptide chain (Figure 4). In this way it forms 6 edges of a tetrahedron, while the flexible linkers were positioned at vertices. The polypeptide was produced in the recombinant form in E. coli and self-assembled by a slow dialysis or temperature annealing into tetrahedral structure, whose edges measure around $5 \mathrm{~nm}$. This direction opens an exciting perspective for the creation of additional entirely new protein folds. The principle of protein assembly can benefit significantly by the application of a mathematical topology theory, which can be used to analyze the number of theoretical solutions and may be in the future applied to optimize the kinetics of the assembly [87]. The results of protein nanocage engineering show that modular design can be used for complex structures, with the potential for applications biocatalysis, targeted drug delivery, vaccination, etc. [88].

\section{Conclusions and future prospects}

The recent successes in the design of new bionanostructures based on DNA and protein demonstrates the potentials of this approach to engineer new functional nanostructures.

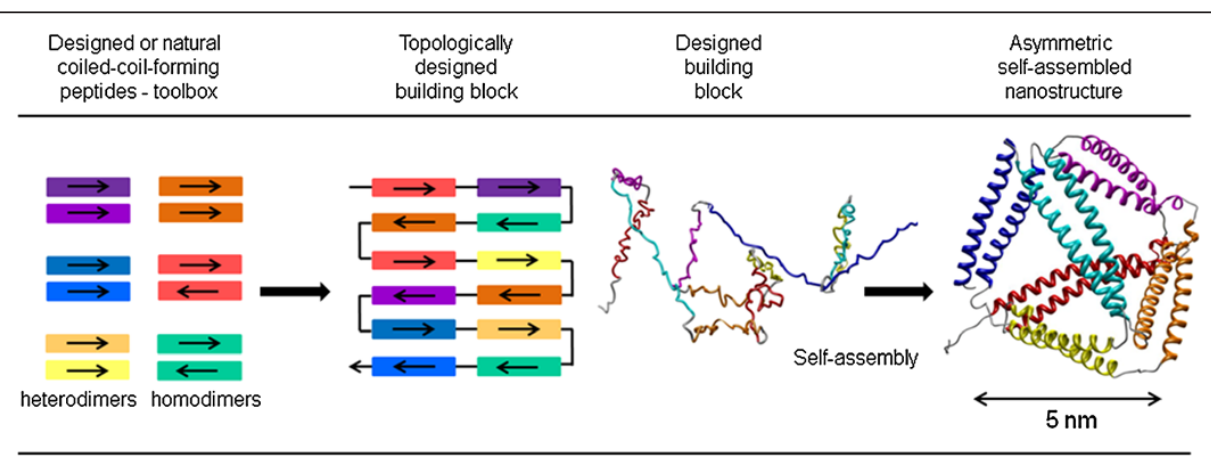

Figure 4 Protein origami: modular topological design of protein structure from a single polypeptide chain. A toolbox for constructing tetrahedron-like cage comprised of six orthogonal pairs of coiled-coil-forming peptides, two antiparallel- and four parallel dimers (orientation is denoted by arrow). Twelve peptides were concatenated in a defined order, separated by the tetrapeptide linker. The single polypeptide chain served as a building block that self-assembled into monomeric and asymmetric tetrahedron-like nanostructure [54]. 
While DNA-based nanostructures are clearly ahead of the designed protein nanostructures in terms of the complexity of the designed structures so far they lacked tangible applications. Although it has been demonstrated that DNA-based nanostructures are functional in organisms, use of in vivo produced and assembled nucleic acid-based nanostructures would represent an important step ahead both for the production cost and new biological applications. Functionalization of nucleic acids could combine structural design with precisely addressed functionalities. However, proteins adopt much larger conformational variability than nucleic acids and provide more versatile functionality. De novo design of protein nanostructures has been limited to small number of application cases which predominatly utilizing repurposed natural protein domains. Nevertheless the design of protein assemblies has matured beyond the proof of principles and is ready to face more complex challenges. New emerging paradigms such as the topological protein folds open completely new avenues that seem not to have been adopted or perhaps even tested by nature. Future developments will demonstrate the potentials of different strategies, or their combinations, with respect to the precise engineering of nanostructures and the theoretical limitations of different platforms. The next stage will need to focus on application development. The potentials are numerous, from targeted drug and biomolecule delivery, vaccine design, tissue engineering, senzors design, biocatalysis to bionanomaterials science. The interdisciplinary approach of synthetic biology, combining structural biology, molecular biology, mathematics, engineering and many other disciplines, have the potential to join forces in this exciting opportunity.

\section{Abbreviations}

2D: Two-dimensional; 3D: Three-dimensional.

\section{Competing interests}

The authors declare that they have no competing interests.

\section{Authors' contributions}

$\mathrm{HG}$ and RJ participated equally in writing this manuscript. Both authors read and approved the final manuscript.

\section{Acknowledgements}

We acknowledge Sabina Božič Abram and Iva Hafner Bratkovič for help in preparing structural images.

\section{Funding}

This work was supported by the EN-FIST Centre of Excellence and program and projects from the Slovenian Research Agency.

Received: 10 December 2013 Accepted: 29 January 2014

Published: 3 February 2014

\section{References}

1. Seeman NC: Nanomaterials based on DNA. Annu Rev Biochem 2010, 79:65-87.

2. Goodman RP, Schaap IAT, Tardin CF, Erben CM, Berry RM, Schmidt CF, Turberfield AJ: Rapid chiral assembly of rigid DNA building blocks for molecular nanofabrication. Science 2005, 310:1661-1665.
3. He Y, Ye T, Su M, Zhang C, Ribbe AE, Jiang W, Mao CD: Hierarchical selfassembly of DNA into symmetric supramolecular polyhedra. Nature 2008, 452:198-U141.

4. Douglas SM, Dietz H, Liedl T, Hogberg B, Graf F, Shih WM: Self-assembly of DNA into nanoscale three-dimensional shapes. Nature 2009, 459:414-418.

5. Andersen ES, Dong M, Nielsen MM, Jahn K, Subramani R, Mamdouh W, Golas MM, Sander B, Stark H, Oliveira CL, Pedersen JS, Birkedal V, Besenbacher F, Gothelf KV, Kjems J: Self-assembly of a nanoscale DNA box with a controllable lid. Nature 2009, 459:73-76.

6. Linko V, Dietz H: The enabled state of DNA nanotechnology. Curr Opin Biotechnol 2013, 24:555-561.

7. Simmel FC: DNA-based assembly lines and nanofactories. Curr Opin Biotechnol 2012, 23:516-521.

8. Zhang DY, Seelig G: Dynamic DNA nanotechnology using strand-displacement reactions. Nat Chem 2011, 3:103-113.

9. Pinheiro AV, Han D, Shih WM, Yan H: Challenges and opportunities for structural DNA nanotechnology. Nat Nanotechnol 2011, 6:763-772.

10. Krishnan Y, Simmel FC: Nucleic acid based molecular devices. Angew Chem 2011, 50:3124-3156.

11. Lo PK, Metera KL, Sleiman HF: Self-assembly of three-dimensional DNA nanostructures and potential biological applications. Curr Opin Chem Biol 2010, 14:597-607.

12. Aldaye FA, Palmer AL, Sleiman HF: Assembling materials with DNA as the guide. Science 2008, 321:1795-1799.

13. Seeman NC: Nucleic acid junctions and lattices. J Theor Biol 1982, 99:237-247.

14. Chen JH, Seeman NC: Synthesis from DNA of a molecule with the connectivity of a cube. Nature 1991, 350:631-633.

15. Ke Y, Ong LL, Shih WM, Yin P: Three-dimensional structures selfassembled from DNA bricks. Science 2012, 338:1177-1183.

16. Shih WM, Quispe JD, Joyce GF: A 1.7-kilobase single-stranded DNA that folds into a nanoscale octahedron. Nature 2004, 427:618-621.

17. Ke Y, Sharma J, Liu M, Jahn K, Liu Y, Yan H: Scaffolded DNA origami of a DNA tetrahedron molecular container. Nano Lett 2009, 9:2445-2447.

18. Bell NA, Engst CR, Ablay M, Divitini G, Ducati C, Liedl T, Keyser UF: DNA origami nanopores. Nano Lett 2012, 12:512-517.

19. Graugnard E, Kellis DL, Bui H, Barnes S, Kuang W, Lee J, Hughes WL, Knowlton WB, Yurke B: DNA-controlled excitonic switches. Nano Lett 2012, 12:2117-2122.

20. Wickham SF, Endo M, Katsuda Y, Hidaka K, Bath J, Sugiyama H, Turberfield AJ: Direct observation of stepwise movement of a synthetic molecular transporter. Nat Nanotechnol 2011, 6:166-169.

21. Qian L, Winfree E: Scaling up digital circuit computation with DNA strand displacement cascades. Science 2011, 332:1196-1201.

22. Qian L, Winfree E, Bruck J: Neural network computation with DNA strand displacement cascades. Nature 2011, 475:368-372.

23. Yurke B, Turberfield AJ, Mills AP Jr, Simmel FC, Neumann JL: A DNA-fuelled molecular machine made of DNA. Nature 2000, 406:605-608.

24. Omabegho T, Sha R, Seeman NC: A bipedal DNA Brownian motor with coordinated legs. Science 2009, 324:67-71.

25. Zhang C, Ko SH, Su M, Leng Y, Ribbe AE, Jiang W, Mao C: Symmetry controls the face geometry of DNA polyhedra. J Am Chem Soc 2009, 131:1413-1415.

26. Rothemund PW: Folding DNA to create nanoscale shapes and patterns. Nature 2006, 440:297-302.

27. Han D, Pal S, Nangreave J, Deng Z, Liu Y, Yan H: DNA origami with complex curvatures in three-dimensional space. Science 2011, 332:342-346.

28. Douglas SM, Marblestone AH, Teerapittayanon S, Vazquez A, Church GM, Shih WM: Rapid prototyping of 3D DNA-origami shapes with caDNAno. Nucleic Acids Res 2009, 37:5001-5006.

29. Kuzuya A, Komiyama M: DNA origami: fold, stick, and beyond. Nanoscale 2010, 2:310-322.

30. Shih WM, Lin C: Knitting complex weaves with DNA origami. Curr Opin Struct Biol 2010, 20:276-282.

31. Wei B, Dai M, Yin P: Complex shapes self-assembled from single-stranded DNA tiles. Nature 2012, 485:623-626.

32. Liu Q, Song C, Wang ZG, Li N, Ding B: Precise organization of metal nanoparticles on DNA origami template. Methods 2013. doi: 10.1016/j. ymeth.2013.10.006

33. Garibotti AV, Perez-Rentero S, Eritja R: Functionalization and self-assembly of DNA bidimensional arrays. Int J Mol Sci 2011, 12:5641-5651.

34. Williams BA, Lund K, Liu Y, Yan H, Chaput JC: Self-assembled peptide nanoarrays: an approach to studying protein-protein interactions. Angew Chem 2007, 46:3051-3054. 
35. Lee JB, Roh YH, Um SH, Funabashi H, Cheng W, Cha JJ, Kiatwuthinon P, Muller DA, Luo D: Multifunctional nanoarchitectures from DNA-based ABC monomers. Nat Nanotechnol 2009, 4:430-436

36. Nakata E, Liew FF, Uwatoko C, Kiyonaka S, Mori Y, Katsuda Y, Endo M, Sugiyama $H$, Morii T: Zinc-finger proteins for site-specific protein positioning on DNA-origami structures. Angew Chem 2012, 51:2421-2424.

37. Delebecque CJ, Lindner AB, Silver PA, Aldaye FA: Organization of intracellular reactions with rationally designed RNA assemblies. Science 2011, 333:470-474

38. Conrado RJ, Wu GC, Boock JT, Xu H, Chen SY, Lebar T, Turnsek J, Tomsic N, Avbelj M, Gaber R, Koprivnjak T, Mori J, Glavnik V, Vovk I, Bencina M, Hodnik V, Anderluh G, Dueber JE, Jerala R, Delisa MP: DNA-guided assembly of biosynthetic pathways promotes improved catalytic efficiency. Nucleic Acids Res 2012, 40:1879-1889.

39. Li Z, Wei B, Nangreave J, Lin C, Liu Y, Mi Y, Yan H: A replicable tetrahedral nanostructure self-assembled from a single DNA strand. J Am Chem Soc 2009, 131:13093-13098.

40. Sobczak JP, Martin TG, Gerling T, Dietz H: Rapid folding of DNA into nanoscale shapes at constant temperature. Science 2012, 338:1458-1461.

41. Douglas SM, Bachelet I, Church GM: A logic-gated nanorobot for targeted transport of molecular payloads. Science 2012, 335:831-834

42. Liu X, Xu Y, Yu T, Clifford C, Liu Y, Yan H, Chang Y: A DNA nanostructure platform for directed assembly of synthetic vaccines. Nano Lett 2012, 12:4254-4259.

43. Mohri K, Nishikawa M, Takahashi N, Shiomi T, Matsuoka N, Ogawa K, Endo M, Hidaka K, Sugiyama H, Takahashi Y, Takakura Y: Design and development of nanosized DNA assemblies in polypod-like structures as efficient vehicles for immunostimulatory CpG motifs to immune cells. ACS nano 2012, 6:5931-5940.

44. Li J, Pei H, Zhu B, Liang L, Wei M, He Y, Chen N, Li D, Huang Q, Fan C: Self-assembled multivalent DNA nanostructures for noninvasive intracellular delivery of immunostimulatory CpG oligonucleotides. ACS nano 2011, 5:8783-8789.

45. Kuhlman B, Dantas G, Ireton GC, Varani G, Stoddard BL, Baker D: Design of a novel globular protein fold with atomic-level accuracy. Science 2003, 302:1364-1368.

46. Fleishman SJ, Whitehead TA, Ekiert DC, Dreyfus C, Corn JE, Strauch EM, Wilson IA, Baker D: Computational design of proteins targeting the conserved stem region of influenza hemagglutinin. Science 2011, 332:816-821.

47. Regan L, Degrado WF: Characterization of a helical protein designed from 1st principles. Science 1988, 241:976-978.

48. Hecht MH, Richardson JS, Richardson DC, Ogden RC: Denovo design, expression, and characterization of felix - a 4-helix bundle protein of native-like sequence. Science 1990, 249:884-891.

49. Dill KA, MacCallum JL: The protein-folding problem, 50 years on. Science 2012, 338:1042-1046.

50. Levy ED, Boeri Erba E, Robinson CV, Teichmann SA: Assembly reflects evolution of protein complexes. Nature 2008, 453:1262-1265.

51. Yeates TO: Nanobiotechnology: protein arrays made to order. Nat Nanotechnol 2011, 6:541-542

52. Lai YT, King NP, Yeates TO: Principles for designing ordered protein assemblies. Trends Cell Biol 2012, 22:653-661.

53. Bozic $S$, Doles $T$, Gradisar $H$, Jerala R: New designed protein assemblies. Curr Opin Chem Biol 2013, 17:940-945.

54. Gradisar H, Bozic S, Doles T, Vengust D, Hafner-Bratkovic I, Mertelj A, Webb B, Sali A, Klavzar S, Jerala R: Design of a single-chain polypeptide tetrahedron assembled from coiled-coil segments. Nat Chem Biol 2013, 9:362-366.

55. Padilla JE, Colovos C, Yeates TO: Nanohedra: using symmetry to design self assembling protein cages, layers, crystals, and filaments. Proc Nat Acad Sci U S A 2001, 98:2217-2221.

56. Lai YT, Cascio D, Yeates TO: Structure of a 16-nm cage designed by using protein oligomers. Science 2012, 336:1129.

57. Lai YT, Tsai KL, Sawaya MR, Asturias FJ, Yeates TO: Structure and flexibility of nanoscale protein cages designed by symmetric self-assembly. J Am Chem Soc 2013, 135:7738-7743.

58. Doles T, Bozic S, Gradisar H, Jerala R: Functional self-assembling polypeptide bionanomaterials. Biochem Soc Trans 2012, 40:629-634.

59. Sinclair JC, Davies KM, Venien-Bryan C, Noble ME: Generation of protein lattices by fusing proteins with matching rotational symmetry. Nat Nanotechnol 2011, 6:558-562
60. Grueninger D, Treiber N, Ziegler MO, Koetter JW, Schulze MS, Schulz GE: Designed protein-protein association. Science 2008, 319:206-209.

61. Leaver-Fay A, Tyka M, Lewis SM, Lange OF, Thompson J, Jacak R, Kaufman K, Renfrew PD, Smith CA, Sheffler W, Davis IW, Cooper S, Treuille A, Mandell DJ, Richter F, Ban YE, Fleishman SJ, Corn JE, Kim DE, Lyskov S, Berrondo M, Mentzer S, Popović Z, Havranek JJ, Karanicolas J, Das R, Meiler J, Kortemme T, Gray JJ, Kuhlman B: ROSETTA3: an object-oriented software suite for the simulation and design of macromolecules. Methods Enzymol 2011, 487:545-574.

62. King NP, Sheffler W, Sawaya MR, Vollmar BS, Sumida JP, Andre I, Gonen T, Yeates TO, Baker D: Computational design of self-assembling protein nanomaterials with atomic level accuracy. Science 2012, 336:1171-1174.

63. Apostolovic B, Danial M, Klok HA: Coiled coils: attractive protein folding motifs for the fabrication of self-assembled, responsive and bioactive materials. Chem Soc Rev 2010, 39:3541-3575.

64. Woolfson DN, Ryadnov MG: Peptide-based fibrous biomaterials: some things old, new and borrowed. Curr Opin Chem Biol 2006, 10:559-567.

65. Bromley EH, Channon K, Moutevelis E, Woolfson DN: Peptide and protein building blocks for synthetic biology: from programming biomolecules to self-organized biomolecular systems. ACS Chem Biol 2008, 3:38-50.

66. Woolfson DN, Bartlett GJ, Bruning M, Thomson AR: New currency for old rope: from coiled-coil assemblies to alpha-helical barrels. Curr Opin Struct Biol 2012, 22:432-441.

67. Ghadiri MR, Granja JR, Buehler LK: Artificial transmembrane ion channels from self-assembling peptide nanotubes. Nature 1994, 369:301-304.

68. Woolfson DN: The design of coiled-coil structures and assemblies. Adv Protein Chem 2005, 70:79-112.

69. Mason JM, Muller KM, Arndt KM: Considerations in the design and optimization of coiled coil structures. Methods Mol Biol 2007, 352:35-70

70. Gradisar H, Jerala R: De novo design of orthogonal peptide pairs forming parallel coiled-coil heterodimers. J Pept Sci 2011, 17:100-106.

71. Fletcher JM, Boyle AL, Bruning M, Bartlett GJ, Vincent TL, Zaccai NR, Armstrong CT, Bromley EH, Booth PJ, Brady RL, Thomson AR, Woolfson DN: A basis set of de novo coiled-coil Peptide oligomers for rational protein design and synthetic biology. ACS Synth Biol 2012, 1:240-250.

72. Thompson KE, Bashor CJ, Lim WA, Keating AE: SYNZIP protein interaction toolbox: in vitro and in vivo specifications of heterospecific coiled-coil interaction domains. ACS Synth Biol 2012, 1:118-129.

73. Zaccai NR, Chi B, Thomson AR, Boyle AL, Bartlett GJ, Bruning M, Linden N, Sessions RB, Booth PJ, Brady RL, Woolfson DN: A de novo peptide hexamer with a mutable channel. Nat Chem Biol 2011, 7:935-941.

74. Thomas F, Boyle AL, Burton AJ, Woolfson DN: A Set of de novo designed parallel heterodimeric coiled coils with quantified dissociation constants in the micromolar to Sub-nanomolar regime. J Am Chem Soc 2013, 135:5161-5166.

75. Bromley EH, Sessions RB, Thomson AR, Woolfson DN: Designed alphahelical tectons for constructing multicomponent synthetic biological systems. J Am Chem Soc 2009, 131:928-930.

76. Ryadnov MG, Woolfson DN: Engineering the morphology of a selfassembling protein fibre. Nat Mater 2003, 2:329-332.

77. Dong H, Paramonov SE, Hartgerink JD: Self-assembly of alpha-helical coiled coil nanofibers. J Am Chem Soc 2008, 130:13691-13695.

78. Peng $X$, Jin J, Nakamura $Y$, Ohno T, Ichinose I: Ultrafast permeation of water through protein-based membranes. Nat Nanotechnol 2009, 4:353-357.

79. Ueda M, Makino A, Imai T, Sugiyama J, Kimura S: Rational design of peptide nanotubes for varying diameters and lengths. J Pept Sci 2011, 17:94-99.

80. Knowles TP, Oppenheim TW, Buell AK, Chirgadze DY, Welland ME: Nanostructured films from hierarchical self-assembly of amyloidogenic proteins. Nat Nanotechnol 2010, 5:204-207.

81. Gour N, Mondal S, Verma S: Synthesis and self-assembly of a neoglycopeptide: morphological studies and ultrasound-mediated DNA encapsulation. J Pept Sci 2011, 17:148-153.

82. Banwell EF, Abelardo ES, Adams DJ, Birchall MA, Corrigan A, Donald AM, Kirkland M, Serpell LC, Butler MF, Woolfson DN: Rational design and application of responsive alpha-helical peptide hydrogels. Nat Mater 2009, 8:596-600.

83. Banta S, Wheeldon IR, Blenner M: Protein engineering in the development of functional hydrogels. Annu Rev Biomed Eng 2010, 12:167-186.

84. Fletcher JM, Harniman RL, Barnes FR, Boyle AL, Collins A, Mantell J, Sharp TH, Antognozzi M, Booth PJ, Linden N, Miles MJ, Sessions RB, Verkade P, 
Woolfson DN: Self-assembling cages from coiled-coil peptide modules. Science 2013, 340:595-599.

85. Raman S, Machaidze G, Lustig A, Aebi U, Burkhard P: Structure-based design of peptides that self-assemble into regular polyhedral nanoparticles. Nanomedicine 2006, 2:95-102.

86. Boyle AL, Bromley EH, Bartlett GJ, Sessions RB, Sharp TH, Williams CL, Curm PM, Forde NR, Linke H, Woolfson DN: Squaring the circle in peptide assembly: from fibers to discrete nanostructures by de novo design. J Am Chem Soc 2012, 134:15457-15467.

87. Fowler PW, Pickup BT, Todorova TZ, Pisanski T: Fragment analysis of singlemolecule conduction. J Chem Phys 2009, 130:174708.

88. Der BS, Kuhlman B: Cages from coils. Nat Biotechnol 2013, 31:809-810.

doi:10.1186/1477-3155-12-4

Cite this article as: Gradišar and Jerala: Self-assembled bionanostructures: proteins following the lead of DNA nanostructures. Journal of Nanobiotechnology 2014 12:4.

\section{Submit your next manuscript to BioMed Central and take full advantage of:}

- Convenient online submission

- Thorough peer review

- No space constraints or color figure charges

- Immediate publication on acceptance

- Inclusion in PubMed, CAS, Scopus and Google Scholar

- Research which is freely available for redistribution 